Original Research

\title{
Development of Detection Instrument Models for Mobility Impairment in The Older Adults Based on A Mobile Health Nursing Application in A Public Health Center
}

\author{
Riksa Wibawa Resna', Lutfan Lazuardi ${ }^{2}$, Sri Werdati ${ }^{3}$ and Wasilah Rochmah ${ }^{4}$ \\ ${ }^{1}$ College of Health Sciences of Banten, Indonesia \\ 2 University of Gadjah Mada, Yogyakarta, Indonesia \\ ${ }^{3}$ University of Alma Ata, Yogyakarta, Indonesia \\ ${ }^{4}$ Medical Faculty, University of Gadjah Mada, Yogyakarta, Indonesia
}

\section{ABSTRACT}

Introduction: Mobility impairment is a problem in the older adults who have decreased in mobility as it may affect their daily activity. The development of a detection model to identify the problem of mobility impairment in older adults has become a solution that can increase the health care for older adults. This study aimed to develop a health detection instrument models using a mobile health nursing application to detect mobility impairment in older adults.

Methods: This study used action research through a purposive sampling method involving three nurses and twenty-seven cadres to perform the detection process of mobility impairment focused on one hundred and seventy-five older adults in three public health centers in two provinces using an m-health application.

Results: Based on direct observation and questionnaires addressed to the user of the m-health nursing application, $80 \%$ stated that the information contained in the mobile health nursing application was appropriate. In terms of speed, only $43.33 \%$ stated that the application worked fast, but overall, $66.67 \%$ of users stated that they were delighted with the application-based of the instrument model and that they were helped in detecting the mobility disorders that occurred in the older adults.

Conclusion: These applications can be developed into a model that can help nurses, older adults and their family to detect other older adult problems in addition to mobility problems like cognitive function etc.
\end{abstract}

\section{ARTICLE HISTORY}

Received: Dec 26, 2019

Accepted: Dec 31, 2019

\section{KEYWORDS}

mobility impairment; telenursing; mobile health nursing

\section{CONTACT}

Riksa Wibawa Resna $\triangle$ riksawibawa@stikesbanten.ac.id $\doteq$ College of Health Sciences of Banten, Indonesia

Cite this as: Resna, R. W., Lazuardi, L., Werdati, S., \& Rochmah, W. (2019). Development of Detection Instrument Models for Mobility Impairment in The Older Adults Based on A Mobile Health Nursing Application in A Public Health Center. Jurnal Ners, 14(3si), 86-92. doi:http://dx.doi.org/10.20473/in.v14i3(si).16970

\section{INTRODUCTION}

Indonesia, as one of the countries with a high population growth rate for the older adult percentage, is estimated to be included in the top 5 countries with an older adult population of 18.1 million or around $9.6 \%$ of the total population. This number will continue to increase up to 28.8 million people or around $11.34 \%$ of the total population in Indonesia in 2020 (Kementerian Koordinator Bidang Kesejahteraan Rakyat RI, 2013).The increase in the number of older adult people will also have an impact on increasing the dependency ratio, where Indonesia in 2008 was at the level of $0-17 \%$. This number will continue to increase year to year. In the years 20202030, dependence between productive and nonproductive ages will reach 44\%(Department of Economic and Social Affairs (DESA) United Nations, 2013).

Health problems are problems that cannot be avoided by older adults. The health problems of the older adults are characterized by various complaints that are multi-pathologic, thus being caused by the multiple impairments suffered by older adults. This can have an impact on the occurrence of dysfunction, disability, disease and complications(Boehlke, 2015). 
Based on the data from the Basic Health Research (Riskesdas) of the Ministry of Health of the Republic of Indonesia, it showed that the most common cause of death in older adult people over the age of 65 years was a stroke, with an occurrence of $20.6 \%$ in men and $24.4 \%$ in women(Kementerian Kesehatan RI, 2018).

The impairment of the musculoskeletal system of older adults is one of the problems faced by the older adults. Difficulty walking, stiffness in the lower legs and soreness are some of the problems that are often reported. Some of these complaints are associated with several joint degenerative diseases such as rheumatoid arthritis, polymyalgia rheumatic and osteoarthritis. The biggest problem of mobility experienced by the older adult majority is in the lower body functions, where the older adults have difficulties walking. The level of difficulty in walking is essential in measuring the health status of the older adults. The older adults who cannot walk are indicated as older adults with a poor health status and they have worse overall functions compared to those who do not experience mobility problems(Satariano et al., 2016).

Seeing the magnitude of the impact caused by the occurrence of impairments in older adults, the role of health workers is essential so then the process of impairment experienced by the older adults does not continue to worsen. The role of the health services starts from the level of the most basic health care, which is the primary health care level. It is indispensable at performing the early detection of problems. In Indonesia, efforts to detect impairment in older adults have not been made even at the level of primary care. Older adult services refer to a service that cannot be considered easy that is especially related to the function and role of the health center which aims to provide promotive and preventive services. The problems and organ function decline experienced by the older adults, until now, had not received special attention in the majority of health centers in Indonesia so the services provided by the health center are still complained about. The absence of a system that functions to detect the setbacks that occur in the older adults is an unusual concern for researchers, considering that the decline process experienced by the older adults will have a considerable impact on the older adults themselves. The occurrence of various organ dysfunctions will have an impact on the inability of older adults to function, as they may experience pain and various complications.

The purpose of this study is to develop a system of services and further health protection by using information systems and technology applications called m-health nursing. The prototype software that will be made is expected to assist the officials in the primary health center as primary health care is able to conduct the early detection of mobility impairment in older adults. The m-health nursing prototype is expected to be used independently by the public health center officers to detect older adult mobility problems directly in the community.

\section{MATERIALS AND METHODS}

This research was carried out to detect the deterioration problem of the musculoskeletal system that occurs in older adults by using an instrument developed based on several instruments that have been used in general. The development of these instruments is expected to assist the health workers at the primary service level such as nurses and cadres in order for them to carry out early detection, monitoring and alertness in the process of the mobility impairments experienced by the older adults. The development of a software prototype application to detect the mobility impairments experienced by the older adults requires several stages, where at each stage, an evaluation will be carried out to achieve the desired results.

In the first stage, the researchers conducted a preliminary study on the locations that were used as the research sites to carry out the process of observing and recording the activities carried out by the officers when providing services to the older adults at the public health center and posyandu. At this stage, the researcher aimed to look at the process that had been carried out by the public health center officers in detecting the problems of mobility experienced by the older adults such as moving disorders, walking disorders or the ability to perform their daily activities.

In the second stage, the researcher created an early detection system model by compiling instruments made by researchers based on the older adult health cards issued by the Indonesian Ministry of Health, ICF Checklist version 2.1a, the Older Adult Mobility Scale, and the Barthel Index Modified Instruments. In the third stage, a trial of the implementation of the compiled instrument model was conducted to measure the effectiveness of the instrument model in the effort to detection mobility impairments in older adults. In this stage, the instruments were analyzed for validity and reliability in order to assess the feasibility of the instruments.

The fourth stage, the implementation of the early detection instrument model, was evaluated to translate the findings that can be applied into the trial phase carried out in the next stage in the form of a software prototype. The fifth stage, after the software prototype was assessed to see if it was able to function to translate the information collected by the officers in the early detection of the mobility impairments experienced by the older adults, the prototype software will be applied in the mobile health nursing application system. In the sixth stage, the researcher evaluated the effectiveness of the use of the m-health nursing application by comparing the effectiveness and efficiency between the users.

The entire research process was carried out in two different provinces, namely Gamping 1 Health Center in the special region of Yogyakarta, Pondok Ranji Health Center and Serpong 1 Health Center located in the South Tangerang City area. The sample in the study consisted of three nurses and twenty-seven 
R. W. RESNA, ET AL.

Table 1. Validity and reliability test results of the m-health nursing instrument questionnaire

\begin{tabular}{|c|c|c|c|}
\hline Variable & Item & r-value (nurse) & r-value (cadres) \\
\hline \multirow{3}{*}{ History of falls } & Question 1 & 0.904 & 0.972 \\
\hline & Question 2 & 0.990 & 0.998 \\
\hline & Alpha-Cronbach & 0.667 & 0.686 \\
\hline \multirow{3}{*}{ History of the disease } & Question 1 & 0.917 & 0.807 \\
\hline & Question 2 & 0.988 & 0.974 \\
\hline & Alpha-Cronbach & 0.720 & 0.608 \\
\hline \multirow{5}{*}{ History of smoking } & Question 1 & 0.869 & 0.944 \\
\hline & Question 2 & 0.999 & 0.975 \\
\hline & Question 3 & 0.999 & 0.966 \\
\hline & Question 4 & 0.999 & 0.657 \\
\hline & Alpha-Cronbach & 0.941 & 0.856 \\
\hline \multirow{4}{*}{ Rest pattern } & Question 1 & 0.973 & 0.858 \\
\hline & Question 2 & 0.995 & 0.995 \\
\hline & Question 3 & 0.998 & 0.995 \\
\hline & Alpha-Cronbach & 0.882 & 0.837 \\
\hline \multirow{7}{*}{ Exercise pattern } & Question 1 & 0.885 & 0.813 \\
\hline & Question 2 & 0.704 & 0.791 \\
\hline & Question 3 & 0.737 & 0.769 \\
\hline & Question 4 & 0.925 & 0.874 \\
\hline & Question 5 & 0.674 & 0.806 \\
\hline & Question 6 & 0.566 & 0.806 \\
\hline & Alpha-Cronbach & 0.781 & 0.867 \\
\hline \multirow{7}{*}{ Current complaints } & Question 1 & 0.972 & 0.997 \\
\hline & Question 2 & 0.828 & 0.788 \\
\hline & Question 3 & 0.683 & 0.841 \\
\hline & Question 5 & 0.722 & 0.476 \\
\hline & Question 6 & 0.811 & 0.936 \\
\hline & Question 7 & 0.976 & 0.996 \\
\hline & Alpha-Cronbach & 0.815 & 0.776 \\
\hline \multirow{7}{*}{ Mobility assessment on bed } & Question 1 & 0.788 & 0.738 \\
\hline & Question 2 & 0.79 & 0.74 \\
\hline & Question 3 & 0.867 & 0.817 \\
\hline & Question 4 & 0.896 & 0.846 \\
\hline & Question 5 & 0.885 & 0.835 \\
\hline & Question 6 & 0.58 & 0.53 \\
\hline & Alpha-Cronbach & 0.685 & 0.612 \\
\hline \multirow{8}{*}{$\begin{array}{l}\text { Mobility assessment while } \\
\text { standing }\end{array}$} & Question 1 & 0.763 & 0.737 \\
\hline & Question 2 & 0.763 & 0.682 \\
\hline & Question 3 & 0.763 & 0.694 \\
\hline & Question 4 & 0.999 & 0.998 \\
\hline & Question 5 & 0.923 & 0.895 \\
\hline & Question 6 & 0.937 & 0.885 \\
\hline & Question 7 & 0.939 & 0.889 \\
\hline & Alpha-Cronbach & 0.884 & 0.865 \\
\hline \multirow{5}{*}{ Mobility assessment in walk } & Question 1 & 0.886 & 0.873 \\
\hline & Question 2 & 0.803 & 0.802 \\
\hline & Question 3 & 0.887 & 0.987 \\
\hline & Question 4 & 0.877 & 0.988 \\
\hline & Alpha-Cronbach & 0.689 & 0.792 \\
\hline \multirow{10}{*}{$\begin{array}{l}\text { Activity daily living } \\
\text { assessment }\end{array}$} & Question 1 & 0.761 & 0.892 \\
\hline & Question 2 & 0.701 & 0.892 \\
\hline & Question 3 & 0.701 & 668 \\
\hline & Question 4 & 0.701 & 0.892 \\
\hline & Question 5 & 0.701 & 0.892 \\
\hline & Question 6 & 0.701 & 0.892 \\
\hline & Question 7 & 0.987 & 0.995 \\
\hline & Question 8 & 0.974 & 0.988 \\
\hline & Question 9 & 0.958 & 0.955 \\
\hline & Alpha-Cronbach & 0.774 & 0.841 \\
\hline
\end{tabular}

posyandu cadres who were responsible for implementing the older adult program in the community. The sample in the study identified mobility impairments using $\mathrm{m}$-health nursing for one hundred seventy-five older adults in the community.

\section{RESULTS}

Based on the results of the validity and reliability tests conducted as many as two times, the tests carried out show that all items in the instrument applied to the 
Table 2. User evaluation of the ability of the m-health nursing application

\begin{tabular}{|c|c|c|}
\hline Aspects evaluated & $\begin{array}{c}\text { Nurse } \\
\%\end{array}$ & $\begin{array}{c}\text { Cadre } \\
\%\end{array}$ \\
\hline \multicolumn{3}{|l|}{ M-health nursing system: } \\
\hline Not in line with expectations & 0 & 7 \\
\hline Less in line with expectations & 33 & 34 \\
\hline In line with expectations & 67 & 52 \\
\hline Exceed expectations & 0 & 7 \\
\hline \multicolumn{3}{|l|}{ Information content } \\
\hline Not in line with expectations & 0 & 4 \\
\hline Less in line with expectations & 67 & 11 \\
\hline In line with expectations & 0 & 81 \\
\hline Exceed expectations & 33 & 4 \\
\hline \multicolumn{3}{|l|}{ Accuracy } \\
\hline Not in line with expectations & 0 & 0 \\
\hline Less in line with expectations & 33 & 4 \\
\hline In line with expectations & 67 & 92 \\
\hline Exceed expectations & 0 & 4 \\
\hline \multicolumn{3}{|l|}{ Form } \\
\hline Not in line with expectations & 0 & 0 \\
\hline Less in line with expectations & 67 & 19 \\
\hline In line with expectations & 33 & 77 \\
\hline Exceed expectations & 0 & 4 \\
\hline \multicolumn{3}{|l|}{ Ease of use } \\
\hline Not in line with expectations & 0 & 4 \\
\hline Less in line with expectations & 33 & 15 \\
\hline In line with expectations & 67 & 59 \\
\hline Exceed expectations & 0 & 22 \\
\hline \multicolumn{3}{|l|}{ Timeliness } \\
\hline Not in line with expectations & 0 & 0 \\
\hline Less in line with expectations & 33 & 15 \\
\hline In line with expectations & 67 & 59 \\
\hline Exceed expectations & 0 & 26 \\
\hline \multicolumn{3}{|l|}{ The speed of the system } \\
\hline Not in line with expectations & 67 & 22 \\
\hline Less in line with expectations & 0 & 8 \\
\hline In line with expectations & 33 & 59 \\
\hline Exceed expectations & 0 & 11 \\
\hline
\end{tabular}

m-health nursing application meet the requirements. The development of instrument models that have been tested for validity and reliability in software prototype m-health nursing has been carried out by involving the programmer in the data flow diagram (DFD) created by the researcher. Once DFD is completed by the researcher, the researcher then scores for each question that will be displayed on the software. This scoring functions is so then the researchers and programmers can summarize the overall results of the observations and the filling in of the nurses and cadres of the medical history, lifestyle, current health conditions and assessment of mobility in older adults. From the total 48 items that will be presented in m-health nursing, only 11 items were used as the basis for scoring for the m-health nursing application, while the 37 other items were additional information for the health workers.

The use of m-health applications in the medical world is not a new thing. Some countries have even made use of this technology for a long time. The research conducted by Moore, Holaday, Meehan, \& Watt (2015) shows that the use of m-health technology is one of the most promising new advances in the field of nursing. The effectiveness of the use of technology engaged in health, in addition to being used to collect data and information about the patients, is that it can now also be used to provide timely and appropriate interventions that are interactive and adaptive so then efforts to deal with one's health condition can be made more quickly. In this study, the $66.67 \%$ level of satisfaction of the users after using the m-health nursing system shows that this m-health-based mobility impairment detection model has exceeded user expectations. The satisfaction of these users is not without reason. Because the evaluation of the M-Health nursing system is related to information content, accuracy, format, convenience, speed, and renewability; most of it has been adjusted to the user's input during the preparation of the instrument. Some things are perceived as lesser by the user because there is still some feedback needed from the users to further develop it. Some of these inputs, among others, include that this application has not usually applied to the IOS operating system, the addition of client photos as an identifier and the client's location positioning using a global positioning system (GPS). Based on this study, we propose a new model of Posyandu services that combines the concept of health center program services with an application following m-health nursing. 


\section{DISCUSSION}

The older adult health program is a development program in the public health center area where the health services not only provide services related to curative efforts but where they also focus on promotive and preventive efforts. This shows that the rate of development of health centers that provide older adults health services and the formation of older adults groups is not in line with expectations with an even distribution(Kemenkes RI, 2015). The mechanism for organizing the older adults posyandu itself is done by collecting the older adults into one particular place to check their health. Based on previous studies, it was shown that many older adult people did not want to come to the posyandu because of the location being far from their homes. Ideally, health workers will go to the older adult people to check their health, especially those who do not go to the older adult posyandu, but they come back again because of the limited number of health workers in the public health center and the uneven distribution of older adult people, making this impossible(Syahid, 2015). Based on the observations within preliminary studies conducted at three public health center, it was found that the services provided at the posyandu included only the measurements of height and weight, in addition to blood pressure checks and noting the general complaints of the older adults. It shows that the treatment of older adults in Indonesia is still focused on treatment; there are no preventive health measures and a comprehensive promotion for the older adults to use to keep themselves productive and happy. Another problem found is that the services of the older adults' posyandu are only done once a month; this is due to the limited human and material resources in the services of the posyandu itself.
With increasing age, functional disorders will increase as indicated by disability. Basic Health Research reported in 2013 that mild disability is measured by the ability to carry out daily living activities or Activity of Daily Living (ADL) and that this is experienced by $51 \%$ of older adults. According to the phenomenon, older adult health services should prioritize promotion and prevention with the support of quality curative and rehabilitative services. This is because the efforts and programs that have been provided by the Indonesian government are not enough to deal with the problems of the older adults related to immobilization. One program in the life cycle approach system is older adult health by screening or early detection. The implementation of early detection related to the older adults is considered to be capable of maintaining the health condition of older adults and furthermore it is expected to prevent the occurrence of disease or further complications of illness in the older adults.

The use of information technology in the present condition is something that cannot be avoided in the development of a detection system. The research conducted by Wang \& Bai, (2013) shows that the application of technology has begun to be able to identify the risk of older adults falling. Research conducted by Aran, Sanchez-Cortes, Do \& GaticaPerez (2016) developed the use of computerized applications to build smart homes that aim to improve the quality of everyday life for older adults. Research conducted by Hou, Lu, Liang, Chen \& Xu (2016) developed a system that can monitor the daily lives of older adults. This system can detect and activate alarms when the parents fall. This system can detect the ability to balance in older adults to prevent them from becoming senile. Based on several models that have been developed, it shows that prevention or screening efforts with a notification system against

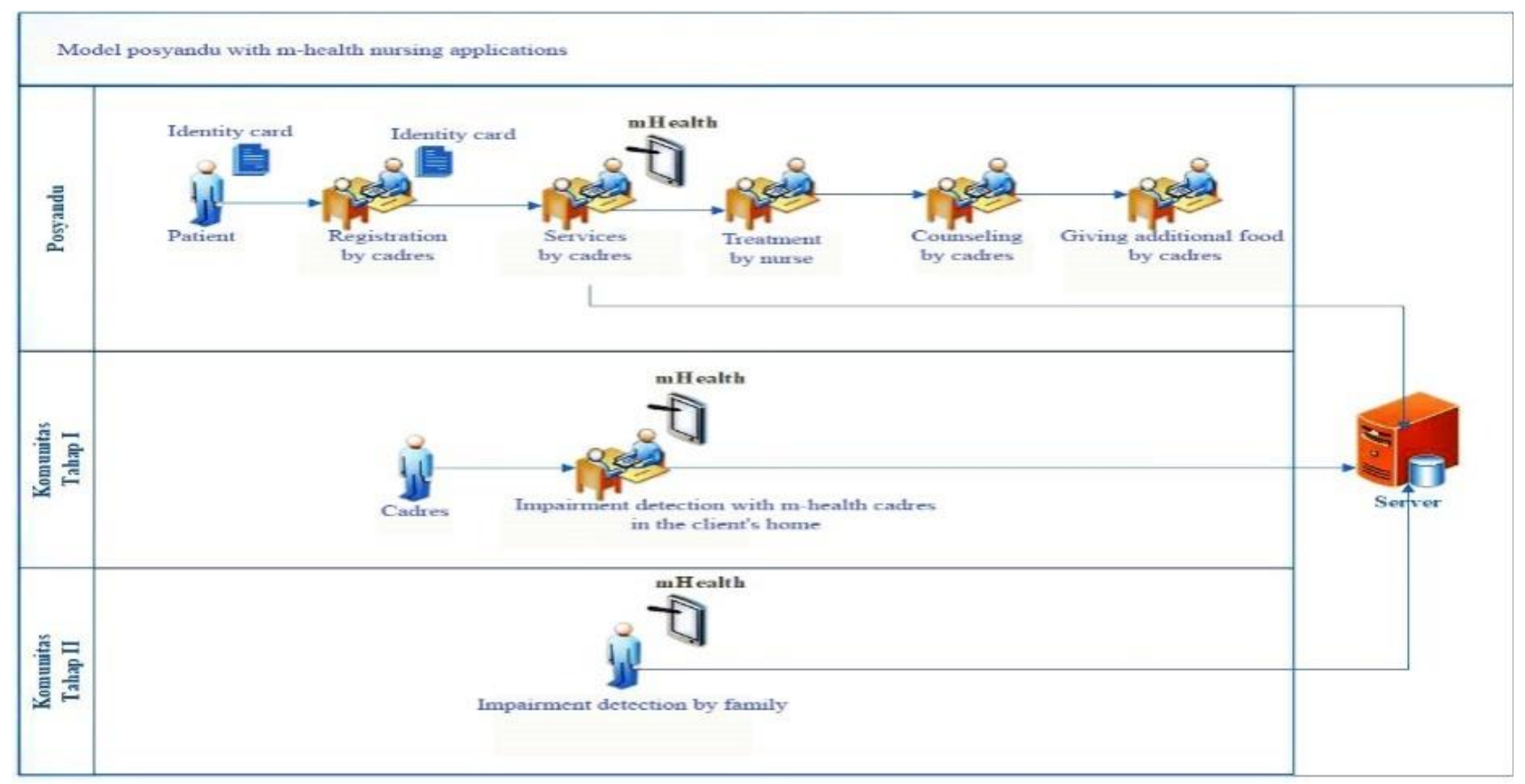

Figure 1. Model posyandu with m-health nursing applications 
the possibility of risks to the older adults are a significant concern. The development of this model is the basis for researchers to develop other detection models that aim to be able to detect mobility problems in older adults, which will have an impact on the possibility of other risks in older adult decreasing, including the risk of falling. The development of the detection model of mobility impairments conducted by the researchers aims to enable older adult people to recognize mobility problems that the families and older adults may not be aware of themselves.

The development of the research instruments was carried out by adopting several instruments. After carrying out the development, a draft instrument for mobility impairment was produced in the form of a manual instrument that was then discussed with the puskesmas officers. After the discussion, the researchers made changes to the instrument by including items that explored the ability of the older adults in carrying out their daily movements and activities. To facilitate data collection in conducting the trial instruments made, the researchers collected data online with the help of a Google form. Based on the results of the preparation and trial of several instruments used in general to be able to detect problems with mobility impairments in older adults, the results of the validity and reliability tests are as follows in Table 1.

After the m-health nursing software prototype was completed and could be appropriately used, the researchers conducted socialization and education focused on the nurses and cadres who will use the mhealth nursing application. Based on the results of the training and the use of $\mathrm{m}$-health nursing to detect mobility impairments as carried out by the posyandu nurses and cadres on one hundred seventy-five older adult people, the researchers evaluated the users. This evaluation aimed to determine the function of the m-health nursing prototype to help in the early detection of mobility impairments experienced by older adults and the ease of the data presented by the nursing m-health prototype will be used to be easily understood and operationalized when used. The evaluation was conducted using the method of enduser computing satisfaction.

Apart from user input, another limitation felt by the researchers was that the application has not been able to thoroughly identify all impairment problems faced by the older adults. Further development is needed concerning the content and interface aspects of this application. The researchers also realize that this application still has to be tested more extensively to be able to see the various shortcomings that exist and so then it can also accommodate the various needs desired by the users when detecting impairment problems in older adults.

\section{CONCLUSION}

The use of mobile technology in the detection of mobility impairment is a choice of model that can be applied in a variety of situations including through mechanisms and the utilization of the cadres' role directly in the community. Prototype m-health nursing can help the nurses and cadres in detecting older adult mobility impairment faster, allowing them to be able to provide recommendations for the nurse and cadres in an intervention for older adults. Based on the results of this study, it showed that m-health nursing applications can be used as one method of detection that can be developed to maintain and improve the health of older adult people in Indonesia. This application is expected to be a basis for the development of other application models that can be used to detect various health problems for older adults. The development of nursing mHealth applications is expected to participate in the national health insurance program so then efforts to improve the health status of the older adults can be more comprehensive and integrated into the national health insurance system to help reduce the health budget nationally.

\section{REFERENCES}

Aran, O., Sanchez-Cortes, D., Do, M. T., \& Gatica-Perez, D. (2016). Anomaly detection in elderly daily behavior in ambient sensing environments. In Lecture Notes in Computer Science (including subseries Lecture Notes in Artificial Intelligence and Lecture Notes in Bioinformatics) (Vol. 9997 LNCS, pp. 51-67). https://doi.org/10.1007/978-3-31946843-3_4

Boehlke, J. (2015). Problems With Elderly Health Care.

Department of Economic and Social Affairs (DESA) United Nations. (2013). World Population Prospects The 2012 Revision.

Hou, Z. J., Lu, Z. Q., Liang, J. Z., Chen, C., \& Xu, Y. (2016). A healthy monitor system for fall and balance detection of elderly. Journal of Mechanical Engineering Research and Developments, 39(2), 364-372.

Kemenkes RI. (2015). Pelayanan dan Peningkatan Kesehatan Lansia.

Kementerian Kesehatan RI. (2018). Riskesdas 2018. Jakarta: Kementerian Kesehatan Republik Indonesia.

Kementerian Koordinator Bidang Kesejahteraan Rakyat RI. (2013). Jumlah Lansia Indonesia, Lima Besar Terbanyak di Dunia Situs Resmi Kementerian Koordinator Bidang Kesejahteraan Rakyat

Moore, S. E., Holaday, B., Meehan, N., \& Watt, P. J. (2015). Exploring mHealth as a new route to bridging the nursing theory-practice gap. Research and Theory for Nursing Practice, 29(1), 38-52. https://doi.org/10.1891/1541-6577.29.1.38

Satariano, W. A., Kealey, M., Hubbard, A., Kurtovich, E., Ivey, S. L., Bayles, C. M., ... Prohaska, T. R. (2016). Mobility disability in older adults: At the intersection of people and places. Gerontologist, 
R. W. RESNA, ET AL.

$56(3)$,

https://doi.org/10.1093/geront/gnu094

Syahid, A. (2015). Kualitas Pelayanan Kesehatan ( Studi Deskriptif tentang Kualitas Pelayanan Kesehatan pada Pasien Usia Lanjut. Jurnal Kebijakan Dan Manajemen Publik, 3(3), 131-137.
Wang, Y., \& Bai, X. Y. (2013). Research of fall detection and alarm applications for the elderly. In Proceedings - 2013 International Conference on Mechatronic Sciences, Electric Engineering and Computer, MEC 2013 (pp. 615-619). https://doi.org/10.1109/MEC.2013.6885137 